\title{
Desafios e perspectivas no ensino de química: uma reflexão a partir da experiência no curso de farmácia do IMMES
}

\section{Challenges and perspectives on teaching chemistry: a look inside the faculty of pharmacy of IMMES}

\author{
Danay Rosa Dupeyron Martell '1, Nádia Rosana Matos Soares ¿2, Ravel Ramos Veiga 3 , \\ Ismael da Silva Nascimento 4, Josemara Pinheiro da Silva 5 , lasmin dos Santos \\ Oliveira 6, Andressa Ketelem Meireles Alberto 7 , Nathalia Thienne Ribeiro dos Santos 8 ,

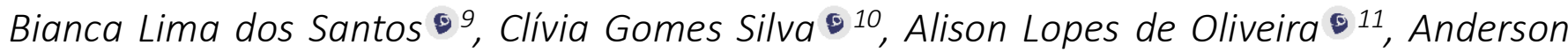 \\ Guilherme Meireles Alberto 12 , Gisele da Silva Botas-Cruz 13
}

\begin{abstract}
${ }^{1}$ Química, Doutora em Biodiversidade Tropical, Professora do Instituto Macapaense do Melhor Ensino Superior. Macapá-AP Brasil. E-mail: danaydm@gmail.com *Autor para correspondência

${ }^{2}$ Farmacêutica, Mestre em Ciências Ambientais, Coordenadora do curso de Farmácia do Instituto Macapaense de Ensino Superior - IMMES.

Macapá-AP Brasil. E-mail: soaresnadia@ig.com.br

${ }^{3}$ Acadêmico de Farmácia do Instituto Macapaense de Ensino Superior. Macapá-AP Brasil. E-mail: ravelrrv@gmail.com

${ }^{4}$ Acadêmico de Farmácia do Instituto Macapaense de Ensino Superior. Macapá-AP Brasil. E-mail: ismaeldasilvanascimento@outlook.com

${ }^{5}$ Acadêmico de Farmácia do Instituto Macapaense de Ensino Superior. Macapá-AP Brasil. E-mail: m.josemarasilva@gmail.com

${ }^{6}$ Acadêmico de Farmácia do Instituto Macapaense de Ensino Superior. Macapá-AP Brasil. E-mail: iasmin.16olvr@gmail.com

${ }^{7}$ Acadêmico de Farmácia do Instituto Macapaense de Ensino Superior. Macapá-AP Brasil. E-mail: andressaketelem@gmail.com

${ }^{8}$ Acadêmico de Farmácia do Instituto Macapaense de Ensino Superior. Macapá-AP Brasil. E-mail: tienne-22@hotmail.com

${ }^{9}$ Acadêmico de Farmácia do Instituto Macapaense de Ensino Superior. Macapá-AP Brasil. E-mail: bialm17gh@gmail.com

${ }^{10}$ Acadêmico de Farmácia do Instituto Macapaense de Ensino Superior. Macapá-AP Brasil. E-mail: cliviags@outlook.com

${ }^{11}$ Acadêmico de Farmácia do Instituto Macapaense de Ensino Superior. Macapá-AP Brasil. E-mail: alisonlopes.al@gmail.com

${ }^{12}$ Acadêmico de Farmácia do Instituto Macapaense de Ensino Superior. Macapá-AP Brasil. E-mail: anderson18guilherme@gmail.com

${ }^{13}$ Doutora em Química de Produtos Naturais, Laboratório de Nanobiotecnologia Fitofarmacêutica - UNIFAP; Professora do Instituto Macapaense de Ensino Superior. Macapá-AP Brasil.E-mail: giselebotas@gmail.com
\end{abstract}

\section{Palavras-chave}

Ensino de Química

Formação de Farmacêuticos

Práticas Educativas

Macapá

IMMES
O ensino de química apresenta-se como um dos grandes desafios do sistema educacional brasileiro. No nível superior, em particular, enfrenta problemas que se iniciam no ensino médio e se refletem quando os alunos entram na universidade. No contexto macapaense, o cenário é ainda mais crítico devido a diversos fatores locais tais como a falta de: boa base do ensino médio, profissionais da área; bons laboratórios, entre outros. Diante deste contexto, e somado a falta de motivação observada por parte dos acadêmicos do curso de farmácia com relação às matérias de química, o presente trabalho tem por objetivo promover uma reflexão a respeito do processo de ensino-aprendizagem de química no curso de farmácia do Instituto Macapaense de Melhor Ensino Superior (IMMES). Para isto, realizou-se uma investigação exploratória, com emprego de abordagem qualitativa, baseada em dados primários obtidos através da aplicação de um questionário. Dentre os aspectos gerais de maior relevância observados neste trabalho encontram-se que: 100\% dos acadêmicos entrevistados são de nacionalidade brasileira, sendo 63\% do sexo feminino; a idade média geral foi de 27 anos, mas com uma ampla faixa etária (17-50). Observou-se também, que o curso conta com um elevado número de estudantes-trabalhadores (65\%). Com relação aos aspectos específicos, relacionados ao ensino de química, chamou a atenção o fato de $56,4 \%$ dos alunos nunca terem realizados atividades práticas no ensino médio. Os resultados mostraram que a maioria dos acadêmicos (60\%) classificou os conhecimentos adquiridos de química no ensino médio como razoáveis ou péssimos. No entanto, a complexidade de conteúdo desta ciência revelouse como a principal dificuldade encontrada pelos discentes. Cabe destacar que os dados levantados através desta pesquisa servirão como ponto de partida para a preparação dos acadêmicos do curso de farmácia do IMMES para o Exame Nacional de Desempenho de Estudantes (ENADE).

Teaching chemistry is one of the greatest challenges of the Brazilian educational system. In particular, chemistry education at the university faces problems that begin in the high school. In the context of the Macapá city, the situation is even more critical since the education system is failing due to local factors (poor quality of high school and poor laboratories conditions, etc). In this regard, and taking into account the students' lack of motivation in chemistry, the present work aims to reveal why we encounter learning gaps on the part of our students on teaching chemistry at the faculty of pharmacy at the Instituto Macapaense do Melhor Ensino Superior (IMMES). Hence, in this study, a qualitative approach by using questionnaire has been used o connect some background and descriptive data of the students' perceptions. Some general aspects related to the social 
context were relevant: all the students are Brazilian, being $63 \%$ of the women sex; the mean age was 27 years, while a broad age range was observed (17-50). Furthermore, 65\% of the respondents are working students. Regarding the teaching chemistry, it worth to note that $56.4 \%$ of the students never performed practical activities in high school. Also, most of the students (60\%) classified their knowledge of chemistry in high school as reasonable or bad. However, the complexity of this science was established to be the main difficulty encountered by most of students. The obtained results in the present study will be considered as a starting point for the preparation of our academics for the National Examination of Student Performance (ENADE).

\section{INTRODUÇÃO}

O ensino de química no Brasil enfrenta grandes desafios no que diz respeito à sua aplicação e aprendizado. Problemas que iniciam no ensino médio se refletem quando os alunos chegam ao ensino superior. Fatores como: a metodologia de ensino-aprendizagem, a pouca abordagem da interdisciplinaridade assim como a falta de aplicação no cotidiano, tem gerado um grande desinteresse dos acadêmicos por essa matéria (ROCHA; VASCONCELOS, 2016). Sabe-se que a química tem uma relação direta com o cotidiano, embora não seja vista desta maneira, mas o fato é de que deve-se motivar o aluno ao ensino desta ciência tão importante para a vida (BOESDORFER, 2015; WALBERG; PAIK, 2000). Portanto, mostra-se necessária a aplicação de métodos que visem despertar o interesse, a capacidade de raciocinar e entender a importância do conhecimento da química para o cotidiano através de experiências científicas com o uso de materiais alternativos presentes no nosso dia a dia (SANTOS et al., 2016; SILVA et al., 2017; MARKIC; CHILDS, 2016).

De acordo com Lessa e Prochnow (2017), para que possam ser superados os desafios enfrentados pelo ensino de química, deve-se observar desde a formação dos professores até as metodologias aplicadas. Propostas atuais de ensino de ciência visam atividades nas quais os alunos desenvolvam uma formação cidadã crítica, através da elaboração de hipóteses e soluções para um problema proposto (ADBO, 2012; ROSA; SUART; MARCONDES, 2017).

Diante deste contexto, e somado ao fato dos alunos do curso de farmácia ter uma imagem distorcida sobre a química, chegando ao ponto de considerá-la não fazer parte de seu cotidiano, o presente estudo tem por finalidade promover a reflexão e identificar as principais dificuldades relacionadas ao aprendizado de química apresentadas pelos alunos do Curso de Farmácia do Instituto Macapaense de Melhor Ensino Superior (IMMES).

\section{REFERENCIAL TEÓRICO}

\section{Ensino de química}

A química está presente em tudo. Partindo deste pressuposto, imagina-se que o ensino de química transmita uma aprendizagem significativa aos alunos, levando os mesmos a associarem teoria e prática, tornando esta ciência uma experiência positiva que aflore a busca pelo saber, onde o aluno possa aprofunda-se nos conhecimentos químicos e desenvolver suas habilidades, visando assim prepará-lo para o avanço na carreira acadêmica (STRACK; MARQUES; PINO, 2009).

Os conhecimentos de química são essenciais em muitas carreiras e, principalmente, na formação universitária de profissionais da saúde. Historicamente, a busca da humanidade por meios de conseguir usar os recursos naturais a seu favor, seja na produção de novos materiais ou na cura de doenças, constituiu um dos principais meio de evolução da química. Assim, a química é um elemento fundamental na medicina moderna, tornando imprescindível que estudantes de nível superior com formação em áreas da saúde saibam compreendê-la e aplicá-la (SANTANA, 2018).

Infelizmente, incertezas sobre a importância e necessidade desta disciplina, como parte do currículo acadêmico, são evidentes. Um episódio muito comum entre estudantes de graduação em farmácia é a dificuldade em aprender química. Expressões como "não gosto de química" ou "é uma matéria muito difícil" são frequentes entre graduandos destes cursos. Em muitos casos, o desinteresse observado durante o período de graduação, reflete a precariedade do ensino de química no nível médio (SANTANA, 2018).

Vale ressaltar que as competências e habilidades cognitivas desenvolvidas através do ensino de química deverão capacitar os alunos a tomarem suas próprias decisões em situações problemáticas, contribuindo assim para o desenvolvimento do educando como pessoa humana e como cidadão (MENEZES et al., 2018). Neste sentido, o professor tem um papel fundamental para demonstrar aos alunos a vital importância de estudar química. O ideal seria 
que cada aluno entendesse que a química não é uma disciplina isolada, pois contribuiu para o desenvolvimento de uma visão crítica de mundo, permitindo analisar, compreender, e o mais importante, usar este conhecimento adquirido em sala de aula, para resolver possíveis problemas cotidianos, apontando o bem-estar social (ZABALA, 2007).

\section{Dificuldades de aprendizagem}

A aprendizagem se dá através da relação interpessoal e intersubjetivo entre o aluno, professor e o objeto de estudo, para que isso ocorra é necessário que essa relação seja de diálogo e confiança recíprocos. Isso propiciará meios para o desenvolvimento crítico e humano tanto do professor como do aluno (VYGOTSKY, 1987). Mesmo o professor tendo bom ânimo, transmitindo motivação e confiança durante o ensino na sala de aula, as dificuldades de aprendizagem ainda se fazem presentes (SILVA; CRISTINA, 2016).

Além das dificuldades encontradas pelos alunos, a maioria deles não compreende a importância em estudar química, o que evidência que a disciplina não está sendo trabalhada de forma adequada (PAZ et al., 2010). Observase, às vezes, que nem o professor de fato entende o verdadeiro sentido em estudar e ensinar química para farmacêuticos (SILVA, 2016).

Durante o ensino médio, muitos alunos ainda não escolheram a profissão e, portanto, não se interessam sobre a importância em aprender química, no "achismo" de que esta disciplina não servirá como base para a futura profissão. Quando o aluno chega ao ensino superior é que ele percebe as lacunas em determinadas disciplinas, criando assim um estereótipo de que aquela disciplina é um tormento ou de que escolheu o curso errado.

Santos et al. (2013) realizaram um estudo com 95 alunos da 1a série do ensino médio de três escolas da rede pública estadual de ensino no município de Aracaju/SE, onde foi possível identificar as dificuldades de aprendizagem em química em cinco categorias: 1) ausência de base matemática, 2) complexidade dos conteúdos, 3) metodologia dos professores, 4) déficit de atenção e 5) dificuldades de interpretação. Isso indica que o ensino está sendo realizado de forma descontextualizada e não interdisciplinar.

Mesmo com as orientações dos Parâmetros Curriculares Nacionais de Química, a maioria das escolas dá ênfase à transmissão de conteúdo e à memorização de fatos, símbolos, nomes, fórmulas, o que coloca de lado a formação do conhecimento científico dos alunos e a desvinculação entre conhecimento químico e o cotidiano (MENEZES et al., 2018). Esse episódio influencia negativamente na aprendizagem dos alunos, já que eles não conseguem visualizar a relação entre o que estudam em sala de aula com a natureza e a sua própria vida (MIRANDA; COSTA, 2007). Isso mostra que nem sempre o professor está apto a atuar de forma interdisciplinar (VEIGA; QUENENHENN; CARGNIN, 2013).

Vários autores indicam que para obter resultados positivos no processo ensino e aprendizagem, se faz necessário o aumento das atividades experimentais em laboratórios, no entanto, em escolas da rede de ensino público isso não é possível, já que estas não dispõem de laboratórios voltados para essa finalidade (GONÇALVES; GALEAZZI, 2004; SILVA; ZANON, 2000; HODSON, 1994). Contudo, essa situação poderia ser contornada com a criação de projetos que possam ser colocados em práticas sem necessariamente usar laboratórios químicos.

\section{Contexto Macapaense}

Macapá, capital do estado do Amapá, localizado no extremo norte do território brasileiro, tem um antigo e extenso histórico com a química. Suas terras têm um alto poder mineral, de onde são extraídos diversos materiais químicos que são trabalhados e comercializados, obtendo alto valor financeiro a quem os detém, servindo assim de influência no mercado consumidor (NETO et al., 2012).

O Brasil tem uma grande carência de profissionais na área de química, sendo esta falta maior em estados menos populosos, como o Amapá, onde há problemas na integração do quadro de profissionais de química para atuarem no ensino, devido principalmente a falta de formação de profissionais da área no próprio estado.

Atualmente, o estado conta com três cursos de graduação em licenciatura em química. O primeiro curso criado no estado é ofertado na Universidade Estadual do Amapá (UEAP), desde que foi autorizada sua criação através da Lei no. 0969, de 31 de março de 2006, e Lei no. 0996, de 31 de maio de 2006, que o institui.

O segundo curso, baseado na Lei de Diretrizes e Bases da Educação Nacional - LDBEN a 9394/96 instituiu-se a partir de agosto de 2011, no Instituto Federal de educação, ciência e tecnologia do Amapá (IFAP) com a finalidade de prover o mercado de trabalho com novos profissionais da educação na área das Ciências Exatas e da Terra.

O terceiro e mais recente curso no estado, que teve sua primeira turma no segundo semestre de 2015, é ofertado na Universidade Federal do Amapá (UNIFAP). A priori este curso conta com um colegiado composto por 10 professores especialistas, mestres ou doutores nas diversas áreas da química.

Levando em consideração o curto período de implementação dos cursos de licenciatura em química no estado, pode-se entender o contingente reduzido de 
Danay Rosa Dupeyron Martell, Nádia Rosana Matos Soares, Ravel Ramos Veiga, Ismael da Silva Nascimento, Josemara Pinheiro da Silva, lasmin dos Santos Oliveira, Andressa Ketelem Meireles Alberto, Nathalia Tienne Ribeiro dos Santos, Bianca Lima dos Santos, Clivia Gomes Silva, Alison Lopes de Oliveira, Anderson Guilherme Meireles Alberto, Gisele da Silva Botas-Cruz.

profissionais atuante na área, fato que influencia diretamente na criação de programas institucionais e a alta evasão dos acadêmicos nesta área da ciência.

Entre tanto, a criação desses cursos é uma garantia para uma mudança no cenário macapaense e, permitirá a formação de profissionais capacitados que possam dar à nossa região um ensino de qualidade, contribuindo para o desenvolvimento local, visando sempre o benefício de toda a sociedade.

\section{Contexto no curso de farmácia do IMMES}

As expectativas do ensino de química no curso de Farmácia do Instituto Macapaense do Melhor Ensino Superior (IMMES) são as melhores, dando prioridade ao aprendizado do aluno e principalmente ao nivelamento do conhecimento adquirido no ensino médio devido à grande dificuldade apresentada pelos acadêmicos nas matérias de química. Assim, a coordenação do curso de farmácia investe em uma formação completa dos alunos na área de química, incentivando o uso dos recursos que a própria instituição disponibiliza, como consultas a periódicos, consultas em livros da biblioteca, participações em atividades complementares como simpósios, semanas acadêmicas, palestras e visitas técnicas, entre outras.

Atualmente, o curso conta com um total de dez professores capacitados nas diferentes disciplinas relacionadas à área de química, como: química geral, química orgânica I e II, química farmacêutica, fitoquímica, farmacognosia, entre outras. No entanto, a coordenadora do referido curso afirma ter apresentado grande dificuldade em contratar professores capacitados para lecionar, em virtude da própria região, que se encontra bastante carente.

\section{METODOLOGIA}

O presente estudo trata de uma investigação exploratória, com emprego de abordagem metodológica qualitativa, baseada em dados primários obtidos através da aplicação de um questionário semiestruturado aos acadêmicos matriculados no segundo semestre de 2018, no Curso de Farmácia com formação generalista implantado no IMMES. De acordo com Chaer, Diniz e Ribeiro (2011), é recorrente o emprego de questionários enquanto técnica de coleta de dados nas pesquisas devido a que os mesmos permitem o levantamento de uma grande quantidade de dados, como também o seu emprego nas pesquisas de cunho qualitativo.

O questionário, estruturado em dois blocos de questões e um quadro referente às características do respondente (sexo, idade, tipo de estudante e nacionalidade) foi composto de
11 perguntas fechadas, conforme reportado nas Tabelas 1 e 2. O mesmo foi elaborado e aplicado pela equipe da Liga Acadêmica de Química do IMMES (LAQUIMMES) e revisado por duas professoras e a coordenadora do curso de farmácia. O questionário foi também revisado por dois professores externos à equipe de pesquisa. Procurou-se aplicar o questionário a todos os alunos do curso de farmácia, mas por razões de logística optou-se por não incluir a turma do décimo semestre noturno (FA10NA). Portanto, participaram da pesquisa os estudantes das restantes turmas dos períodos curriculares (semestres) vigentes no momento da aplicação do questionário: segundo, quarto, sexto e oitavo semestres noturnos de farmácia (FA2NA, FA4NA, FA6NA, FA8NA).

Tabela 1. Relação de questões gerais do questionário aplicado aos estudantes do Curso de Farmácia.

\section{DE CARÁTER GERAL}

1.1. Em qual estado brasileiro você realizou seus estudos de ensino médio?

( ) Amapá

( ) Pará

( ) Outro

( ) Nenhum

1.2. Você realizou seus estudos de ensino médio em uma escola:
( ) Pública
( ) Privada
( ) Ambas
( ) Outras

1.3. Você acha que é preciso estudar química para ser farmacêutico?
( ) Sim, bastante
( ) Sim, pouco
( ) Não sei
( ) Não

1.4. A questão da interdisciplinaridade é abordada em sala de aula?
( ) Sempre
( ) As vezes
() Poucas vezes
( ) Nunca

1.5. Como você avalia a articulação da equipe pedagógica (professores, coordenador acadêmico) de seu curso?

( ) Articulada

( ) Parcialmente articulada

( ) Pouco articulada

( ) Desarticulada

Fonte: Autoria própria

A tabulação, o processamento e a análise dos dados foram realizados e verificados por diferentes acadêmicos da equipe de pesquisa, acompanhados por, no mínimo, um dos professores membros da LAQUIMMES. Para a construção dos gráficos foi empregado o programa Excel. 
Tabela 2. Relação de questões específicas do questionário aplicado aos estudantes do Curso de Farmácia.

\section{QUANTO AO ENSINO DE QUÍMICA}

2.1. Como você classifica os conhecimentos de química adquiridos no ensino médio.
( ) Ótimos
( ) Bons
( ) Razoáveis
( ) Péssimos

2.2. Você realizou atividades de pesquisa ou laboratórios antes de se matricular neste curso?

( ) Muitas

( ) Algumas

( ) Poucas

( ) Nenhuma

2.3. Que dinâmicas de ensino tem sido utilizadas predominante?

( ) Aulas expositivas

( ) Aulas práticas

( ) Trabalhos de grupo

( ) Outras

2.4. Que instrumentos de avaliação presencial são mais adotados?

( ) Provas escritas

( ) Trabalhos de grupo

( ) Trabalhos individuais

() Vários

2.5. Como você avalia as atividades práticas desenvolvidas nos laboratórios de ensino?

( ) Adequadas

( ) Razoavelmente adequadas

( ) Pouco adequada

( ) Inadequadas

2.6. Qual a principal dificuldade enfrentada nas disciplinas de química?

( ) Base do ensino

( ) Complexidade

( ) Metodologia de ensino

( ) Falta de motivação

Fonte: Autoria própria

\section{RESULTADOS E DISCUSSÃO}

Os trabalhos de pesquisa são extremamente importantes na construção do conhecimento científico, servindo para socializá-lo entre os discentes de nível superior como forma de reconhecer e interferir na realidade (CHAER; DINIZ; RIBEIRO, 2011). Na presente pesquisa, o emprego do questionário é uma técnica viável e pertinente, já que se trata de questões de caráter empírico. Assim torna-se importante o envolvimento da opinião dos acadêmicos do curso com vista a desenvolver metodologias que despertem o interesse pelas disciplinas de química (PONTES et al., 2008).

Nesta seção, serão apresentados e discutidos os resultados seguindo a estruturação em dois blocos estabelecida no questionário aplicado. Antes de analisar os blocos de questões serão abordados alguns aspectos relacionados às características gerais do respondente.

\section{Perfil geral do acadêmico de farmácia}

O número total teórico de 132 respondentes encontravase distribuído nos seguintes semestres curriculares: 15 do segundo (11\%); 34 do quarto (26\%); 40 do sexto (30\%); 43 do oitavo (33\%). Desse total de 132 acadêmicos, foram entrevistados 110 respondentes (83\%) distribuídos da seguinte forma: 15 do segundo (11\%); 30 do quarto (23\%); 31 do sexto (23\%); 34 do oitavo (26\%). O restante, 22 acadêmicos (17\%) não foram entrevistados porque estavam ausentes no dia da aplicação do questionário.

Dentre os aspectos gerais de maior relevância observado neste trabalho encontram-se que: $100 \%$ dos acadêmicos entrevistados são de nacionalidade brasileira, sendo $63 \%$ do sexo feminino; a idade média geral foi de 27 anos, mas com uma ampla faixa etária (17-50). Também se observou que o curso conta com um elevado número de estudantestrabalhadores (65\%), sendo que o $41 \%$ corresponde ao sexo

Tabela 3. Perfil geral da pesquisa.

\begin{tabular}{|c|c|c|c|c|c|c|c|c|c|c|}
\hline \multirow[t]{2}{*}{ Turma } & \multicolumn{2}{|c|}{$\begin{array}{c}\text { Acadêmicos } \\
\text { Matriculados* }\end{array}$} & \multicolumn{2}{|c|}{$\begin{array}{c}\text { Acadêmicos } \\
\text { entrevistados* }\end{array}$} & \multicolumn{2}{|c|}{$\begin{array}{c}\text { Idade média } \\
\text { (Anos) }\end{array}$} & \multicolumn{2}{|c|}{$\begin{array}{c}\text { Faixa etária } \\
\text { (Anos) }\end{array}$} & \multicolumn{2}{|c|}{$\begin{array}{l}\text { Estudantes- } \\
\text { trabalhadores* }\end{array}$} \\
\hline & $\mathrm{F}$ & $M$ & $\mathrm{~F}$ & $M$ & $\mathrm{~F}$ & $M$ & $\mathrm{~F}$ & $M$ & $\mathrm{~F}$ & $M$ \\
\hline FA4NA & 18 & 8 & 18 & 9 & 29 & 24 & $19-43$ & $20-30$ & 14 & 8 \\
\hline FA6NA & 14 & 17 & 14 & 14 & 25 & 30 & $19-36$ & $21-50$ & 8 & 10 \\
\hline Total Geral & \multicolumn{2}{|c|}{100} & \multicolumn{2}{|c|}{100} & \multicolumn{2}{|c|}{27} & \multicolumn{2}{|c|}{$17-50$} & \multicolumn{2}{|c|}{65} \\
\hline
\end{tabular}

Fonte: Dados obtidos através do questionário aplicado no presente estudo.

Nota: * Valores expressados em porcentagens 
Danay Rosa Dupeyron Martell, Nádia Rosana Matos Soares, Ravel Ramos Veiga, Ismael da Silva Nascimento, Josemara Pinheiro da Silva, lasmin dos Santos Oliveira, Andressa Ketelem Meireles Alberto, Nathalia Tienne Ribeiro dos Santos, Bianca Lima dos Santos, Clivia Gomes Silva, Alison Lopes de Oliveira, Anderson Guilherme Meireles Alberto, Gisele da Silva Botas-Cruz.

feminino. Outros aspectos sociais gerais dos entrevistados aparecem reportados com detalhe na tabela 3.

\section{Questões de caráter geral}

Quando questionados em qual estado brasileiro realizaram o ensino médio, $85 \%$ dos acadêmicos afirmaram ter realizado no estado do Amapá, $6 \%$ no estado do Pará e $9 \%$ em outros estados brasileiros (Figura 1), o que demonstra que a maior parte dos alunos entrevistados cursaram o ensino médio no estado do Amapá.

Dos alunos entrevistados, mais da metade $(81,8 \%)$ afirmaram que estudaram o ensino médio em escolas da rede de ensino público (Figura 2), onde as vezes enfrentam uma série de dificuldades no que diz respeito a infraestrutura e recursos como laboratórios. No entanto, 94 entrevistados (85,5\%) (Figura 3 ) consideram muito importante o estudo da química, evidenciando que a maioria dos alunos reconhecem a importância desta ciência para a formação do profissional farmacêutico, fato este que tem sido motivo de trabalhos recentes (SANTANA, 2018).

Quanto à questão de a interdisciplinaridade ser abordada em sala de aula, somente $21 \%$ e $55,5 \%$ dos entrevistados respondeu que sempre e às vezes era abordada, respectivamente (Figura 4). Este resultado demonstra que ainda é preciso enfatizar mais o caráter interdisciplinar e a importância da química para os profissionais da saúde (SOUSA; BASTOS, 2016).

No que diz respeito à equipe pedagógica, $34,5 \%$ e $44,6 \%$ afirmam ser articulada ou parcialmente articulada (Figura 5). Esta avaliação da articulação da equipe pedagógica é de extrema importância, visto que esta equipe planeja e trabalha para colocar em prática atividades que são fundamentais na vida acadêmica.

Figura 1. Distribuição dos estados onde os entrevistados realizaram os estudos de ensino médio.

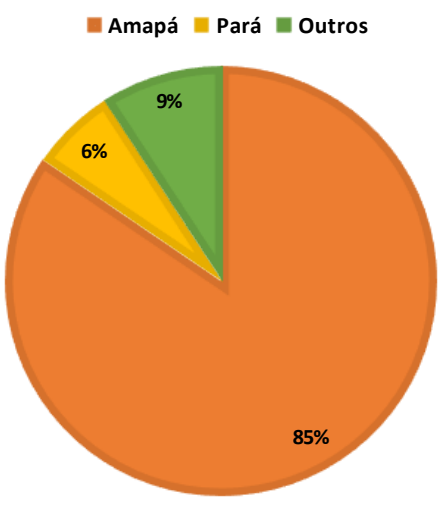

Fonte: Construídos com dados obtidos no presente estudo.
Figura 2. Tipo de escola onde os acadêmicos realizaram os estudos de ensino médio.

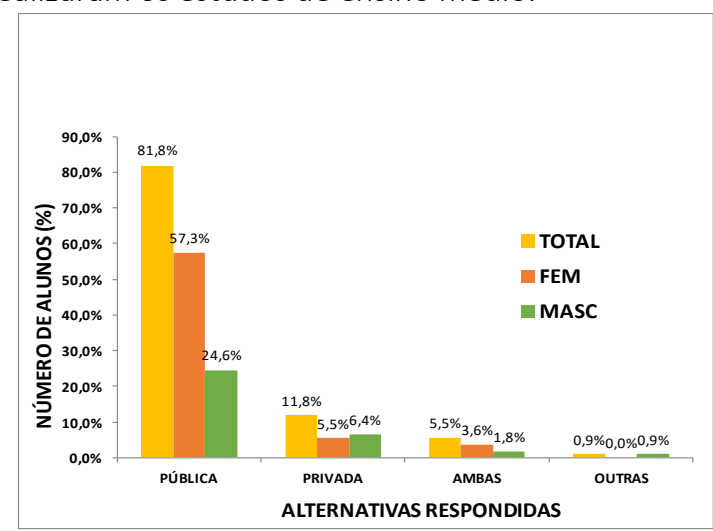

Fonte: Construídos com dados obtidos no presente estudo.

Figura 3. Necessidade de estudar química para ser farmacêutico.

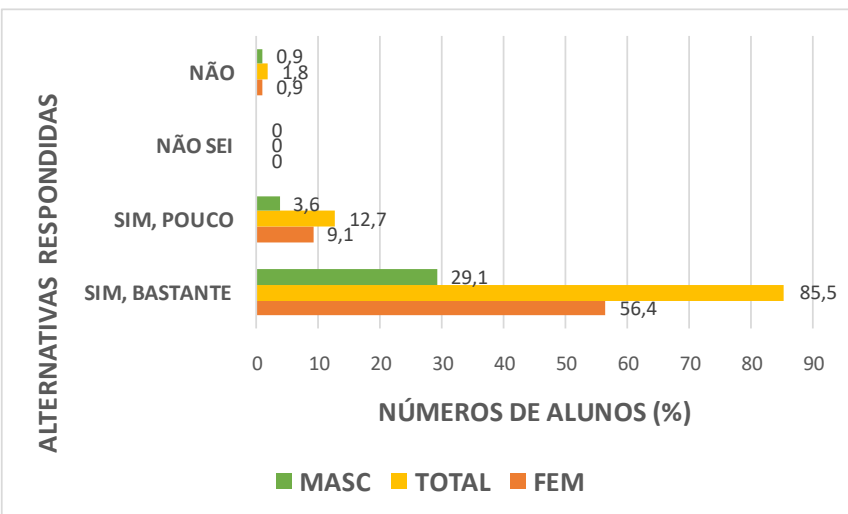

Fonte: Construídos com dados obtidos no presente estudo.

Figura 4. Abordagem da interdisciplinaridade em sala de aula.

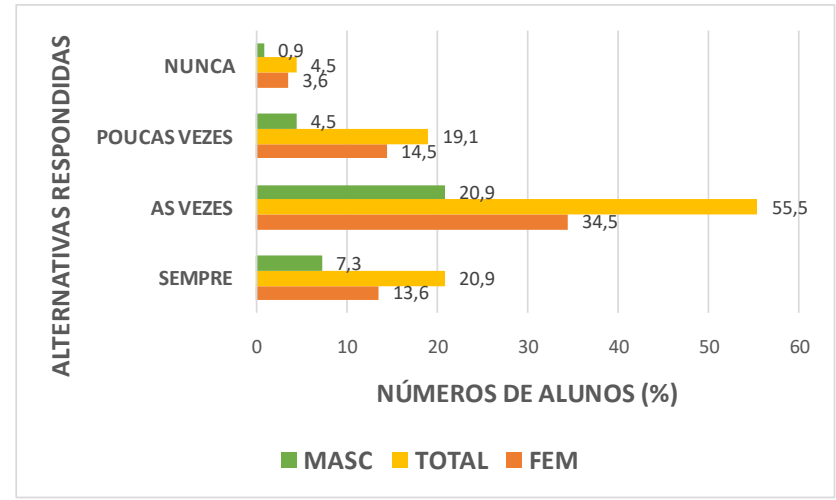

Fonte: Construídos com dados obtidos no presente estudo. 
Figura 5. Articulações da equipe pedagógica (professores, coordenador acadêmico).

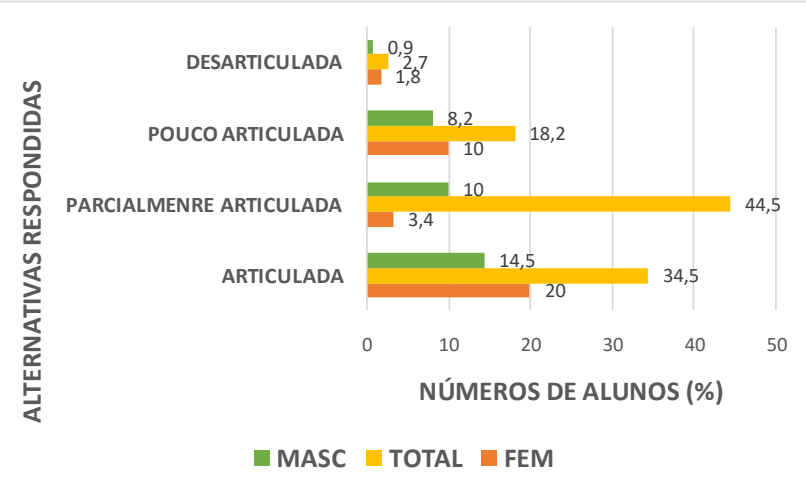

Fonte: Construídos com dados obtidos no presente estudo.

\section{Questões relacionadas ao ensino de química}

Ao iniciar esta reflexão, considera-se súbito, o fato de que a metodologia de aquisição no ensino de química constitui um grande desafio para os educadores, visto que, têm inúmeras formas de se relacionar com o estudo dos conteúdos. Há estudantes que se interessam apenas com os resultados de seus estudos; correspondido pelas notas ou conceitos. Há também, os que visam esclarecimentos profundos da matéria e passam a analisá-la para alcançar uma visão ampla do conhecimento.

Os resultados deste trabalho mostraram que a maioria dos acadêmicos (60\%) classificou os conhecimentos adquiridos de química no ensino médio como razoáveis ou péssimos (Figura 6). Por outro lado, chamou bastante a atenção o fato de $56,4 \%$ dos alunos nunca terem realizados atividades práticas no ensino médio (Figura 7). Quanto às dinâmicas de ensino que tem sido utilizada predominantemente $33,6 \%$ dos entrevistados responderam aulas expositivas (Figura 8). Com relação aos instrumentos de avaliação presenciais mais adotados foi observado que as provas escritas continuam sendo o principal meio de avaliação (Figura 9). Assim, o método de ensino da química utilizado pelos professores em sala de aula é limitado e precisa ser revisto. Neste sentido, fica evidente que é preciso sair do cotidiano de sala de aula (aulas expositivas), principalmente fazendo uso de laboratórios como uma forma de motivação para os alunos (BERTON, 2015; MARTÍNEZ; TORREGROSA, 2015; SOUSA; BASTOS, 2016).

Rolisola (2004) discorre sobre um projeto designado como "A Química da Limpeza", onde os alunos desenvolvem detergentes e sabão líquidos, e assim, a professora aborda os compostos oxigenados e nitrogenados, no que diz respeito à nomenclatura, composição das substâncias que estão ligadas a tais processos, ente outros. Então os alunos se envolvem com o projeto e com os temas abordados, já que eles agora conseguem enxergar a importância do projeto no seu cotidiano. Contudo, para que situações como esta sejam desenvolvidas requer iniciativa por parte do professor (QUADROS; BARROS, 2004). Por isso é indispensável que o professor busque pela formação continuada. Vale também ressaltar que o sucesso no processo de aprendizagem do aluno vai depender da sua motivação para aprender, buscar novos conhecimentos, com garra, entusiasmo e preparo para encarar os desafios que possam ser encontrados (VEIGA; QUENENHENN; CARGNIN, 2013).

Segundo Valente (2009), a didática geral é uma ciência teórica-prática que pesquisa, experimenta e sugere formas de comportamentos a serem adotados no processo de ensino-aprendizagem, resultando na eficiência e eficácia das aulas, sendo ferramenta cotidiana do professor tendo uma contínua evolução, portanto o professor deve se aperfeiçoar e atualizar seu conhecimento sobre novas técnicas que possam ser utilizadas em sala de aula. Além disso, a arte da didática permite ajudar o alunado a aprender química e entender sua importância na vida pessoal e profissional. Para isto, o professor deve estar também atualizado no que ocorre nesta ciência sempre em evolução (BERTON, 2015).

Os resultados apresentados na Figura 10 sugerem que as práticas de laboratórios realizadas na instituição de nível superior podem ainda ser melhoradas. No entanto, a complexidade de conteúdo desta ciência revelou-se como a principal dificuldade encontrada pelos discentes (Figura 11). Diante deste resultado, cabe mencionar que outro fator decisivo no processo de ensino-aprendizagem de química são os livros didáticos oferecidos como suporte das aulas expositivas. Em alguns livros, os textos são apresentados de forma complexa, fazendo necessária a orientação adequada do professor para que o aluno consiga entender a matéria. Fatos como esse, fazem com que a química se torne a grande vilã dos estudantes, pois nem sempre compreendem a disciplina, embora recebam incentivos dos professores.

Figura 6. Classificação dos conhecimentos de química adquiridos no ensino médio.

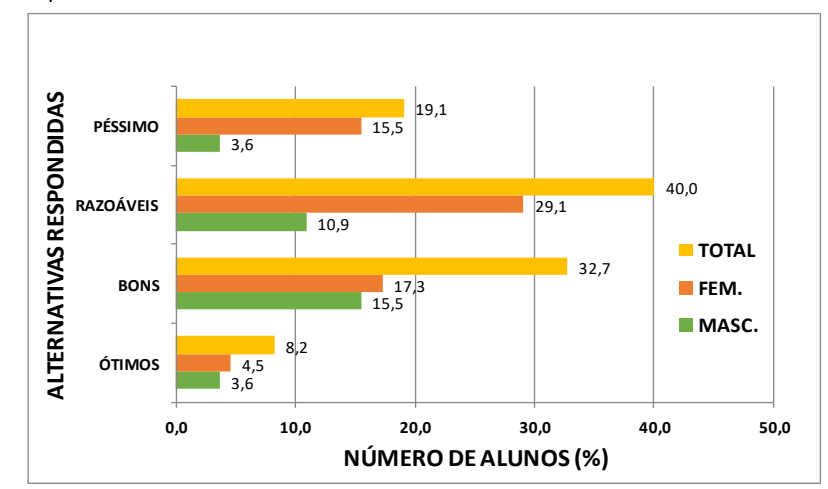

Fonte: Construídos com dados obtidos no presente estudo. 
Danay Rosa Dupeyron Martell, Nádia Rosana Matos Soares, Ravel Ramos Veiga, Ismael da Silva Nascimento, Josemara Pinheiro da Silva, lasmin dos Santos Oliveira, Andressa Ketelem Meireles Alberto, Nathalia Tienne Ribeiro dos Santos, Bianca Lima dos Santos, Clivia Gomes Silva, Alison Lopes de Oliveira, Anderson Guilherme Meireles Alberto, Gisele da Silva Botas-Cruz.

Figura 7. Atividades de pesquisa ou laboratórios realizados antes de matricular no curso superior.

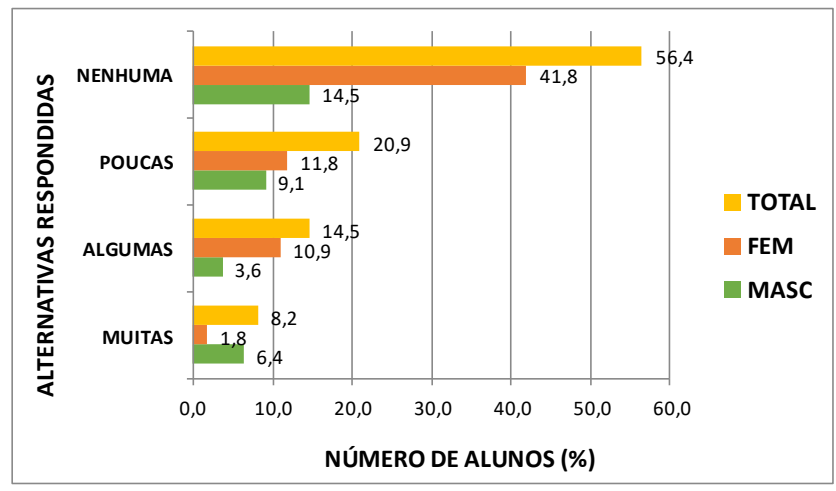

Fonte: Construídos com dados obtidos no presente estudo.

Figura 8. Dinâmicas de ensino utilizadas predominante.

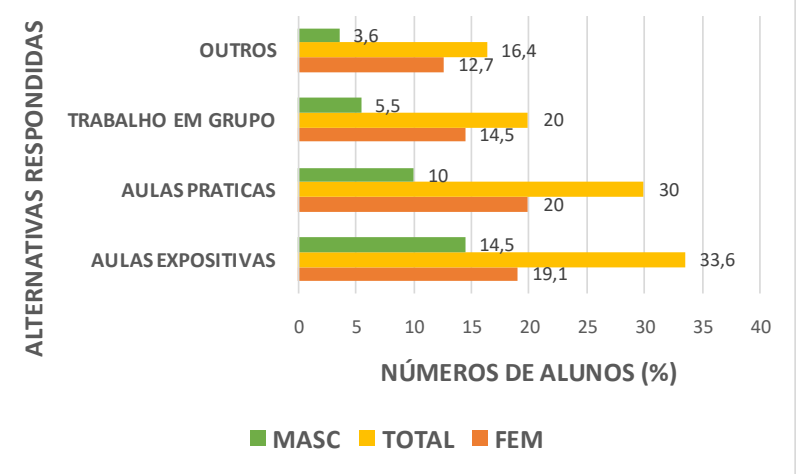

Fonte: Construídos com dados obtidos no presente estudo.

Figura 9. Instrumentos de avaliação presenciais mais adotados.

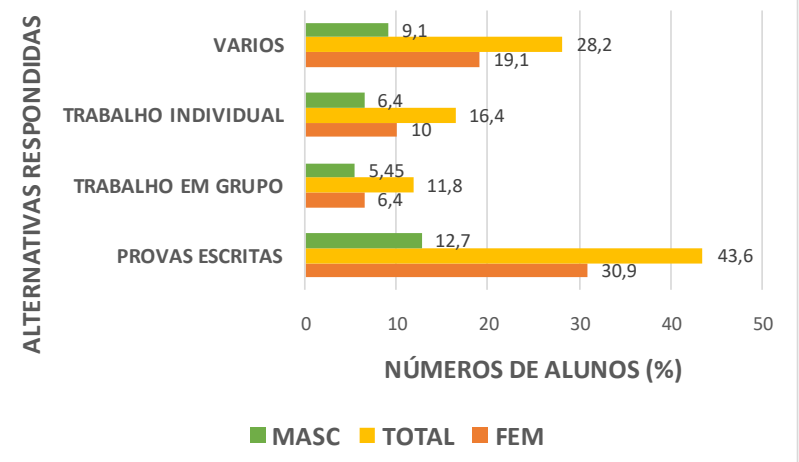

Fonte: Construídos com dados obtidos no presente estudo.

Figura 10. Avaliação das atividades práticas desenvolvidas nos laboratórios.

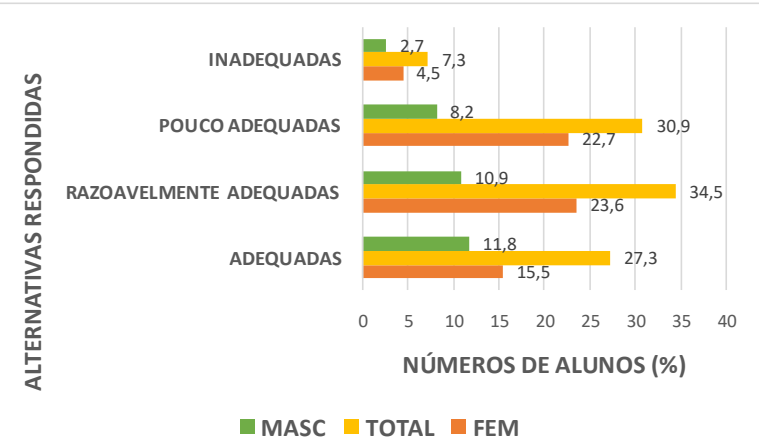

Fonte: Construídos com dados obtidos no presente estudo.
Figura 11. Dificuldades enfrentadas nas disciplinas de química.

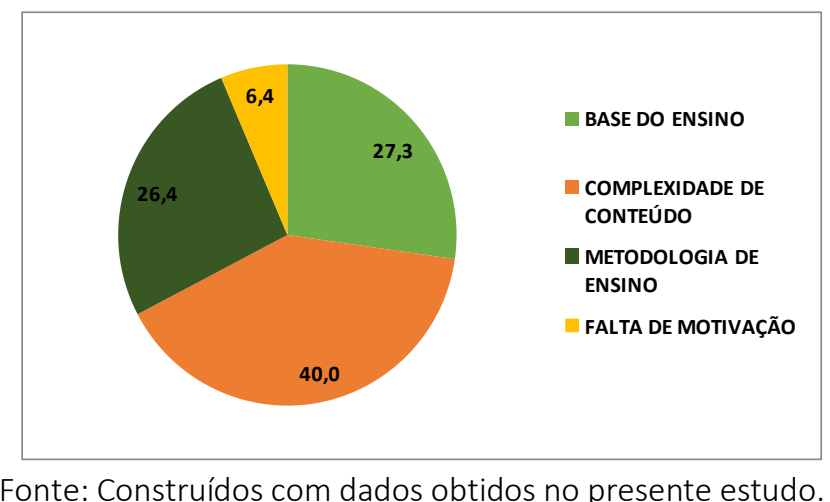

\section{CONCLUSÕES}

O presente estudo permitiu identificar o perfil do acadêmico assim como as principais dificuldades encontradas no ensino de química no curso de farmácia do IMMES. Dentre os aspectos gerais de maior relevância observado neste trabalho encontram-se que o $63 \%$ dos acadêmicos é do sexo feminino; a idade média geral é de 27 anos, mas com uma ampla faixa etária (17-50). Também se observou que o curso conta com um elevado número de estudantes-trabalhadores (65\%). Com relação aos aspectos específicos, relacionados ao ensino de química, chamou bastante à atenção o fato de $56,4 \%$ dos alunos nunca terem realizados atividades práticas no ensino médio. Os resultados mostraram que a maioria dos acadêmicos (60\%) classificou os conhecimentos adquiridos de química no ensino médio como razoáveis ou péssimos. No entanto, a complexidade de conteúdo desta ciência revelou-se como a principal dificuldade encontrada pelos discentes. Neste sentido, consideramos importante mencionar, que as dificuldades encontradas pelos discentes, refletem também aspectos que às vezes passam despercebidos, como: fatores e pressões sociais aos quais os jovens são expostos tanto no ambiente familiar como social, por exemplo, o difícil desafio de ingressar e prosseguir os estudos no nível superior e a necessidade da entrada destes no mercado de trabalho. Estes fatores podem exercer uma grande influência na toma de decisão referente ao futuro dos estudantes.

Com base nos resultados encontrados, pôde-se estabelecer e/ou constatar a realidade em que se encontra o ensino de química no curso de farmácia do IMMES. Isto permitirá traçar as medidas pertinentes para tentar reverter o quadro de falta de motivação e interesse observado entre os acadêmicos do referido curso. Cabe destacar que os dados levantados através desta pesquisa servirão como ponto de partida para o desenvolvimento de novas estratégias pedagógicas no IMMES a fim de melhorar a 
compreensão da química pelos acadêmicos e, assim ratificar o compromisso da instituição com o melhoramento contínuo na formação de profissionais qualificados, o que deverá causar impacto positivo nas avaliações institucionais, como o Exame Nacional de Desempenho de Estudantes (ENADE).

\section{AGRADECIMENTOS}

Os autores agradecem à Direção Geral e à Coordenação do Curso de Farmácia do Instituto Macapaense de Melhor Ensino Superior (IMMES) pelo apoio à pesquisa.

\section{REFERÊNCIAS}

ADBO, K. Relationships between models used for teaching chemistry and those expressed by students. 2012. 978-91 f. Dissertation (Doctorate in natural sciences) Linnæus University,. Printed by: Intellecta Infog, Gothenburg.

BERTON, A. N. B A. Didática no Ensino da Química. In: XII Congresso Internacional de Educação, 25, 2015, Curitiba. Anais XII EDUCERE. Curitiba, out. 2015.

BOESDORFER, S. B. Review of Chemistry Education: Best Practices, Opportunities and Trends Chemistry Education. Journal of Chemical Education, [s.I.], v. 92, n. 12, 13 out. 2015. p. 1975-1976.

CHAER. G.; DINIZ, R. R. P.; RIBEIRO, E. A. A técnica do questionário na pesquisa educacional. Revista Evidência. Araxá, v. 7, n. 7, p. 251-266, 2011.

GONÇALVES, F. P.; GALLIAZI, M.C. A natureza das atividades experimentais no ensino de ciências: um programa de pesquisa educativa nos cursos de Licenciatura. In: MORAES, R.; MANCUSO, R. (Orgs.) Educação em ciências: produção de currículos e formação de professores. ljuí: Unijuí, p. 237-252, 2004.

HODSON, D. Hacia un enfoque más crítico del trabajo de laboratorio. Enseñanza de las Ciencias, [s.I.], v. 12, n. 3, p. 299-313, nov. 1994.

LESSA, G. G.; PROCHNOW, T. R. Ensino da química no Brasil. Interferência historiográfica no perfil acadêmico dos professores que lecionam química na cidade de Valença/BA. Revista Iberoamericana de Educación, [s.I.], v. 73, n. 2, p. 119-142, 2017.

MARKIC, S.; CHILDS, P. E. Language and the teaching and learning of chemistry. Chemistry Education Research And Practice, [s.l.], v.17, n.3, p. 434-438, 2016.

MARTÍNEZ. J. G.; TORREGROSA, E. S. (eds). Chemistry education: best practices, opportunities and trends. Wiley. 2015 | 792pp. ISBN 9783527336050

MENEZES, L. C.; FILHO R. L. B.; PEREIRA, A. R. S.; MAIA, M. E. Parâmetros Curriculares Nacionais (Ensino Médio).
Disponível em: $<$ http://portal.mec.gov.br/seb/arquivos/pdf/ciencian.pdf >. Acesso em: 01 nov. 2018.

MIRANDA, D. G. P.; COSTA, N. S. Professor de Química: Formação, competências/ habilidades e posturas. 2007. Disponível em: <http://www.ufpa.br/eduquim/formdoc.html> Acesso em: 10 nov. 2018.

NETO, I. B. dos S.; SANTOS, L. L.; GOMES, J. E. H.; GONÇALVES, T. da C. A Importância do Curso Licenciatura em Química no Amapá: a situação do curso no Instituto Federal de Educação, Ciência e Tecnologia do AmapáIFAP. In: Congresso Norte Nordeste de Pesquisa e Inovação - CONNEPI, 7, 2012, Palmas. Anais Ciências exatas e da terra - Química. Palmas, 2012. p. 1.

PAZ, G. L.; PACHECO, H.F.; NETO, C. O. C.; CARVALHO, R. de C. P. S. Dificuldades no ensino-aprendizagem de química no ensino médio em algumas escolas públicas da região sudeste de Teresina. In: Simpósio Brasileiro de Educação Química, 8, 2010, Natal. Anais VII SIMPEQUI. Natal, jul. 2010.

PONTES, A. N.; SERRÃO, C. R. G.; DE FREITAS, C. K. A.; DOS SANTOS, D. C. P.; BATALHA, S. S. A. O Ensino de química no nível médio: um olhar a respeito da motivação In: Encontro Nacional de Ensino de Química, 14, 2008, Curitiba. Anais XIV ENEQ. Curitiba, jul. 2008.

QUADROS, A. L. de; BARROS, J. M. Formação Continuada: Compromisso de Todos. In: Congresso Brasileiro De Extensão Universitária, 2, 2004, Belo Horizonte. Anais Área Temática de Educação. Belo Horizonte, 2004. p. 1 6.

ROCHA, J. S.; VASCONCELOS, T. C. Dificuldades de aprendizagem no ensino de química: algumas reflexões, 18, 2016, Florianópolis. Anais XVIII ENEQ. Florianópolis, jul. 2016.

ROLISOLA, A.M.C.M. Projeto de Ensino de Química: "A Química da Limpeza". São Paulo, 2004. Disponível em:< http://gpquae.iqm.unicamp.br/quimlimp.pdf >. Acesso em: 01 nov. 2018.

ROSA, L. M. R.; SUART, R. de. C.; MARCONDES, M. E. R. Regência e análise de uma sequência de aulas de química: contribuições para a formação inicial docente reflexiva. Ciência \& Educação, [s.I.], v. 23, n.1, p. 51-70, mar. 2017.

SANTANA, P. C. de. A importância do ensino de química e seu conhecimento na formação universitária de profissionais da saúde, Disponível em: <https://meuartigo.brasilescola.uol.com.br/quimica/aimportancia-ensino-quimica-seu-conhecimento-naformacao-universitaria-de-profissionais-saude.htm> Acesso em: 15 de outubro de 2018. 
Danay Rosa Dupeyron Martell, Nádia Rosana Matos Soares, Ravel Ramos Veiga, Ismael da Silva Nascimento, Josemara Pinheiro da Silva, lasmin dos Santos Oliveira, Andressa Ketelem Meireles Alberto, Nathalia Tienne Ribeiro dos Santos, Bianca Lima dos Santos, Clivia Gomes Silva, Alison Lopes de Oliveira, Anderson Guilherme Meireles Alberto, Gisele da Silva Botas-Cruz.

SANTOS, A. O.; Silva, R. P.; Andrade, D.; Lima, J. P. M. Dificuldades e motivações de aprendizagem em química de alunos do ensino médio investigadas em ações do (PIBID/UFS/QUÍMICA). Scientia Plena. [s.I.], v. 9, n. 7, p. 01-10, jul. 2013.

SANTOS. M. T. da S.; ARRUDA, C. de A.; SANTANA, M. V. F. da S.; VIANA, K. da S. L. A escolha pela carreira docente em Química: desafios e perspectivas. In: Encontro Nacional de Ensino de Química, 18, 2016, Florianópolis. Anais XVIII ENEQ. Florianópolis, jul. 2016.

SILVA, J. N. da; AMORIM, J. S.; MONTEIRO, L. P.; Freitas, K. H. G. Experimentos de baixo custo aplicados ao ensino de química: contribuição ao processo ensino-aprendizagem. Scientia Plena, [s.l.], v.13, n.1, p. 1-11, jan. 2017.

SILVA, L. H. A.; ZANON, L. B. A experimentação no ensino de Ciências. In: Schnetzler, R. P.; Aragão, R. M. R. (orgs.). Ensino de Ciências: Fundamentos e Abordagens, Piracicaba: Capes/Unimep: Piracicaba, p. 120-153, 2000.

SOUSA, I. F. de; BASTOS, P. R. H. O. Interdisciplinaridade e formação na área de farmácia. Trabalho, Educação e Saúde, [s.l.], v. 14, n. 1, p. 97-117, mar. 2016.

STRACK, R.; MARQUES, M.; del PINO, J. C. Por um outro percurso da construção do saber em educação química. Química Nova na Escola. v. 31, n. 1, p. 18-22, fev. 2009.

VALENTE, N. Didática: ferramenta cotidiana do professor. 2009.

Disponível

em:<http//www.jornaldedebates.uol.com.br/debate/co mo-melhorar-qualidade-educacao-

nobrasil/artigo/didatica-ferramenta-cotidiana-professor>. Acesso em: 01 nov. 2018

VEIGA, M. S. M.; QUENENHENN, A.; CARGNIN, C. O ensino de química: algumas reflexões. In: Jornada De Didática O Ensino Como Foco e Fórum De Professores De Didática Do Estado Do Paraná, 1, 2012, Londrina. Anais Didática e Prática de Ensino na Educação Básica, Londrina: UEL, 2013, p. 189-198.

WALBERG, H.; PAIK, S. Effective educational practices. Brussels, Belgium: International Academy Education. Disponível em:

http://www.ibe.unesco.org/fileadmin/user_upload/archi ve/Publications/educationalpracticesseriespdf/prac03e.p df $>$. Acesso em: 15 de outubro de 2018.

ZABALA, A. A prática educativa: como ensinar. Porto Alegre: Artmed, 1998, reimpresso, 2007. 